\title{
Phytochemical screening and antimicrobial activity of leaves extract of Annona senegalensis from rainforest of Ahmadu Bello University Zaria, Nigeria
}

\author{
Yakubu, Ameenu, Haruna, Idris, Maidaula, Abdussalam Tijjani \\ Department of Chemistry, Faculty of Physical Sciences, Ahmadu Bello University, Zaria, Nigeria
}

\begin{abstract}
Annona senegalensis belongs to the family Annonaceae which is known to possess wide range of bioactivities. The leaves of $A$. senegalensis have been traditionally used as stimulant and a pain reliever. This study aims to determine the presence of some of the bioactive molecules in the leaves of this plant, and further investigate the antimicrobial activity of the extract against certain bacteria. The crude methanolic extract of the leaves was tested for phytochemicals, and revealed the presence of carbohydrates, flavonoids, steroids, saponins, tannins, anthraquinone and cardiac glycosides, and triterpenoids. The crude methanolic extract was purified using column chromatography techniques. The Fourier Transform Infrared Spectroscopy (FT-IR) analysis of the isolated compounds revealed the presence of $\mathrm{C}-\mathrm{H}, \mathrm{C}=\mathrm{O}, \mathrm{O}-\mathrm{H}$ and $\mathrm{C}=\mathrm{C}$ functional groups, which are characteristics of the compounds in the secondary metabolites. The antimicrobial screening of the crude methanol extract was carried out on Escherichia coli, Staphylococcus aureus, Bacillus subtilis, Salmonella typhi and Klebsiella pneumonia, using agar well diffusion method. The antimicrobial screening showed that the extract was active against Staphylococcus aureus, Bacillus subtilis and Escherichia coli. The solvent extract was more effective against Staphylococcus aureus with zones of inhibition of $20 \mathrm{~mm}$ and $18 \mathrm{~mm}$ at a concentration of $100 \mathrm{mg} / \mathrm{ml}$ and $50 \mathrm{mg} / \mathrm{ml}$ respectively. The minimum inhibitory concentration of the crude extract carried out against the test microorganisms were within the range of $12.5-25 \mathrm{mg} / \mathrm{ml}$ while the minimum bactericidal concentration was within the range of $25-50 \mathrm{mg} / \mathrm{ml}$. The result from this study justifies the use of the leaves of Annona senegalensis in treatment of microbial diseases.
\end{abstract}

Keywords: Annona senegalensis, phytochemical, antimicrobial, medicinal plants, Escherichia coli, Staphylococcus aureus, Bacillus subtilis, Salmonella typhi

\section{INTRODUCTION}

$\mathrm{M}$ edicinal plants have so far been studied by natural scientists, and discovered to possess phytochemical constituents which qualifies their relevance in local and modern therapy. Preliminary screening of phytochemicals is a valuable step in the detection of the bioactive components present in medicinal plants, and subsequently may lead to drug discovery and development. Plants such as vegetables, fruit, spices, medicinal herbs, etc., have been used to cure many diseases since ancient time. Nowadays, the preference of using traditional folk medicine over synthetic drugs is still common in some places, even as the latter is readily available and proves very effective as remedy for many diseases. Quite a number compound has been collected from different plant and studied. The compounds that are majorly secondary metabolites exhibited to variable extent, antibacterial, antiviral, anti-inflammatory, analgesic, anticancer, to mention but few. Amongst these phytochemical compounds, as reported by Iqbal et al. (2015), includes flavonoids, terpenoids, saponins and cyanogenic glycosides, phenols and phenolic glycosides, stilbenes, tannins and nitrogen compounds (alkaloids, amines and betalains).

By definition, according to World Health Organization, medicinal plants are those plants with at least one of their organs possessing chemical substances that are primary reactants in chemo-pharmaceutical semi synthesis, or exploited for remedial purposes. Several parts of such plants including the leaves, flowers, fruits, stem barks, roots, rhizomes, seeds or grains, contains medically active components, and are thus utilized for the prevention, treatment and management of human malady (Kar, 2007). These biologically active constituents, phytochemicals (named from the Greek word 'Phyto', meaning 'plant') or phytoconstituents, are non-nutrient plant compounds. Yet, they serve the purpose of protecting the plants from infestation from pests or microbial attacks (Doughari, 2012). Annona senegalensisis of the Annonaceae family is a tropical plant species also known as 'wild custard apple' or 'wild soursop'. It is usually a shrub (2-6 m tall), or small tree (11 m) under some suitable ecological conditions. Several uses of the plant species are reported, for example anti-oxidant, antimicrobial, antidiarrheal, anti-inflammatory, antiparasitic, anticonvulsant, antimalarial, anti-snake venom and many other biomedical properties of pharmaceutical relevance. The phytochemical screening of the leaves extract revealed that Annona senegalensis contains carbohydrates, steroids, cardiac glycosides, flavonoids, tannins, triterpenes, and saponins. The presence of these diverse secondary metabolites in the plant justifies its uses, as antioxidant due to the presence of flavonoids, likewise anti-inflammatory due to the presence of tannins. It is reported to be used to treat many ailments. This includes the use of it leaves decoction as extraordinary remedy for diabetes, yellow fever, small pox and tuberculosis (Ajaiyeoba et al., 2006; Mustapha et al., 2013). Similarly, 
different parts of the tree have been used against snake-bite and hernia treatment (Dambatta and Aliyu, 2011).

An antimicrobial is an agent that kills microorganisms or inhibits their growth. Antimicrobial medicines can be grouped according to the microorganisms they act primarily against, for example antibiotics are used against bacterial and antifungal are used against fungi (Kingston, 2008). The microorganism could be pathogenic or non-pathogenic, hence antimicrobial substances are used in the treatment of various ailments. A quite number of antimicrobial substances exist and they are gotten from diverse sources such as microbial, plants, animals and chemical source (Genellin et al., 1999).

This study focuses on Annona senegalensisis, locally known as 'Gwandar Daji' in the Hausa ethnics of Nigeria (Bala, 2006). The fruit's specific medicinal uses are not much described, but the leaves have been widely used for treating yellow fever, tuberculosis, and small pox Likewise, the roots have been utilized to treat certain issues which includes, snakebite, gastritis, difficulty in swallowing, tuberculosis, detoxification, and for male sexual impotence (Ngbolua et al. 2017).

The objective of the study was to carry out preliminary phytochemical screening. Also, to determine the antimicrobial activities (by MBC and MIC), after the purification and characterization (employing TLC and FT-IR) of $A$. senegalensisis leaves extract collected from the rainforest of Ahmadu Bello University, Zaria. To the best of our knowledge, there has been no study conducted on $A$. senegalensisis collected from Ahmadu Bello University, Zaria, nor published on the phytochemical screening and antimicrobial activity of its leaves extract.

\section{MATERIALS AND METHODS}

\subsection{Plant material and sample preparation}

Adopting the method described by Iqbal et al. (2015); the leaves of Annona senegalensis were collected from rainforest of Ahmadu Bello University Zaria Nigeria in July, 2019. They were rinsed with tap water followed by distilled water to remove dirt on the surface. The clean leaves were then airdried for 3 days and subsequently freeze dried until a constant mass was obtained. The dried samples were ground into fine powder mechanically using wooden mortar and pestle, and kept in the desiccators until extracted. The extraction was carried out with $3.00 \mathrm{~L}$ of methanol by maceration for 48 hours. The solvent was then evaporated at $40^{\circ} \mathrm{C}$ using rotary evaporator and the crude extract was kept in desiccators before analysis.

\subsection{Chemicals and reagents}

All the chemicals used were of analytical grade. Methanol, glacial acetic acid and acetic anhydride were purchased from Jerry House Dog; ethyl acetate and dimethyl sulphoxide (DMSO) from Lobacheil; ciprofloxacin from Dana pharmaceuticals; sulfuric acid $\left(\mathrm{H}_{2} \mathrm{SO}_{4}\right)$, ferric chloride hexahydrate $\left(\mathrm{FeCl}_{3} \cdot 6 \mathrm{H}_{2} \mathrm{O}\right)$, sodium hydroxide $(\mathrm{NaOH})$, ammonia, glycerol, methanol, chloroform, potassium iodide, mercuric chloride, n- hexane, Wagner's reagent, Molisch's reagent, Mayer's reagent were all obtained from the departmental store. All the chemicals were used without further purification.

\subsection{Phytochemical screening}

The crude methanolic extract of the leaves was screened for carbohydrate, glycosides (anthraquinone glycosides and cardiac glycosides), saponins, steroids, terpenes, flavonoids, tannins, and alkaloids, employing standard qualitative procedures as reported by Joshi et al. (2013), Ayoola et al. (2008), and Banso and Adeyemo (2006). The qualitative results are defined as (+) indicating presence and (-) indicating absence of phytochemicals.

\subsubsection{Tests for glycosides}

a) Anthraquinone glycoside (Borntrager's test): To the extract solution $(1 \mathrm{~mL}), 5 \% \mathrm{H}_{2} \mathrm{SO}_{4}(1 \mathrm{~mL})$ was added. The mixture was boiled in a water bath and then filtered. Filtrate was then shaken with equal volume of chloroform and kept to stand for $5 \mathrm{~min}$. Then lower layer of chloroform was shaken with half of its volume with dilute ammonia. The formation of rose pink to red color of the ammoniacal layer gives indication of anthraquinone glycosides.

b) Cardiac glycosides (Keller-Kiliani test): Extract (0.5 g) was shaken with distilled water $(5 \mathrm{~mL})$. To this, glacial acetic acid $(2 \mathrm{~mL})$ containing a few drops of ferric chloride was added, followed by $\mathrm{H}_{2} \mathrm{SO}_{4}(1 \mathrm{~mL})$ along the side of the test tube. The formation of brown ring at the interface gives positive indication for cardiac glycoside and a violet ring may appear below the brown ring.

\subsubsection{Test for steroids and terpenoids (Liebermann-Burchard test)}

Each extract (100 mg) was shaken with chloroform in a test tube; few drops of acetic anhydride were added to the test tube and boiled in a water bath and rapidly cooled in iced water. Concentrated $\mathrm{H}_{2} \mathrm{SO}_{4}(2 \mathrm{~mL})$ was added alongside of the test tube. Formation of a brown ring at the junction of two layers and turning the upper layer to green shows the presence of steroids while formation of deep red color indicates the presence of triterpenoids.

\subsubsection{Test for alkaloids (Wagner's test)}

Potassium iodide $(2 \mathrm{~g})$ and iodine $(1.27 \mathrm{~g})$ were dissolved in distilled water $(5 \mathrm{~mL})$ and the solution was diluted to $100 \mathrm{~mL}$ with distilled water. Few drops of this solution were added to the filtrate; a brown colored precipitate indicates the presence of alkaloids.

\subsubsection{Test for saponins (Frothing test)}

Each of plant extracts (0.5 g) was separately shaken with distilled water $(10 \mathrm{~mL})$ in a test tube. The formation of 
frothing, which persists on warming in a water bath for $5 \mathrm{~min}$, shows the presence of saponins.

\subsubsection{Test for tannins (Ferric-chloride test)}

Extract (leaf and bark, $0.5 \mathrm{~g}$ each) was separately stirred with distilled water $(10 \mathrm{~mL})$ and then filtered. A few drops of $5 \%$ ferric chloride were then added. Black or blue-green coloration or precipitate was taken as positive result for the presence of tannins.

\subsubsection{Test for flavonoids (Shinoda test)}

A portion of the extract was dissolved $1-2 \mathrm{ml}$ of $50 \%$ methanol in the heat metallic magnesium chips and few drops of concentrated hydrochloric acid were added. Appearance of red color indicates presence of flavonoids.

\subsubsection{Test for Carbohydrates (Molisch test)}

To a small portion of the extract in a test tube, few drops of Molisch reagent was added. And, concentrated sulphuric acid was then added down the side of the test tube which resulted to the formation of a lower layer, a reddish-purple colored ring at the interphase indicating the presence of carbohydrates. The ring disappeared on addition of excess alkali.

\subsection{Antimicrobial Screening of Annona senegalensis}

Antimicrobial screening of the crude methanol extract was conducted using some selected pathogens.

\subsubsection{Test Organisms}

The test organisms used for this analysis were clinical isolate of bacteria obtained from department of microbiology, Ahmadu Bello University, Zaria. The isolates were Staphylococcus aureus, Bacillus subtilis, Salmonella typhi, Escherichia coli, Klebsiella pneumoniae. All the microbes were screened for purity, and were maintained in slants of nutrient agar for bacteria, and slants of sabouraud dextrose agar for fungi.

\subsubsection{Preparation of solution of plant extract for antimicrobial screening test}

Well diffusion method was used for the determination of the antimicrobial activities of the extracts. Each crude extract was weighed out and dissolved in $10 \mathrm{ml}$ of Dimethyl sulphoxide (DMSO) to obtain a concentration of $10 \mathrm{mg} / \mathrm{ml}$. This was the initial concentration used to check the antimicrobial activities of the extracts.

\subsubsection{Culture media}

The culture media used include Mueller Hinton agar (MHA), Mueller Hinton broth (MHB), and potato dextrose agar (PDA). All media were prepared according to manufacturer's instructions and sterilized by autoclaving at $121^{\circ} \mathrm{C}$ for 15 minutes (Girish, 2008).

2.4.4. Determination of Inhibitory Activity (Sensitivity Test) of the extract using Agar Well Diffusion Method

The standardized inocula of both the bacterial and fungal isolate were streaked on sterilized Mueller Hinton and potato dextrose agar plates respectively with the aid of sterile swab sticks. Four wells were punched on each inoculated agar plate with a standard sterile cork borer. The well was properly labeled according to different concentrations of the extract prepared which were $100,50,25$, and $12.5 \mathrm{mg} / \mathrm{ml}$ respectively. Each well was filled up with approximately $0.2 \mathrm{ml}$ of the extract.

The inoculators' plate with the extract was allowed to stay on the bench for about one hour; this is to enable the extract to diffuse on the agar. The plates were then incubated at room temperature for 24 hours for the bacteria about 5 days for the fungi.

At the end of incubation period, the plates were observed for any evidence of inhibition which will appear as a clear zone that was completely devoid of growth around the wells (zone of inhibition). The diameter of the zone was measured using transparent ruler calibrator in millimeter and the result was recorded (Andrews, 2001).

\subsubsection{Determination of Minimum Inhibitory Concentrations (MIC) of the Extract}

The minimum inhibitory concentration of the extract was determined using tube dilution method with the Mueller Hinton broth used as diluents. The lowest concentration of the extract showing inhibition for each organism when the extract was tested during sensitivity test was serially diluted in the test tube containing Mueller Hinton broth. The standardized organisms were then incubated at $37^{\circ} \mathrm{C}$ for 25 hours.

At the end of incubation period, the tubes were examined/observed for the presence or absence of growth using turbidity as a criterion, the lowest concentration is the series without visible sign of growth (turbidity), was considered to be the minimum inhibitory concentration (MIC). The result was also recorded (Andrews, 2001).

\subsubsection{Minimum Bactericidal Concentration}

The result from the minimum inhibitory concentration (MIC) was used to determine the minimum bactericidal concentration (MBC) of the extract. A sterilized wire loop was deep into the test tube(s) that did not show turbidity (clear) in the MIC test and a loopful was taken and streaked on sterile nutrient agar plates. The plates were incubated at $37^{\circ} \mathrm{C}$ for 24 hours. At the end of incubation period, the plates were examined/observed for the presence or absence of growth. This is to determine whether the antimicrobial effect of the extract is bacteriostatic or bactericidal (Andrews, 2001).

\subsection{Chromatographic purification of extracts}

\subsubsection{Thin layer chromatography (TLC)}

Thin layer chromatography was carried out using silica precoated aluminum plate. A dilute solution of the ethyl acetate fraction was prepared and spotted in one end of the plate, about $1 \mathrm{~cm}$ from the lower edge using a capillary tube and dipped into the solvent system of hexane : ethyl acetate in the ratio of $(90: 10,80: 20$ and 70:30). Thus, a separation of the 
components was achieved by virtue of the fact that they move at different rates. Separation was stopped by the removal of the plates when the solvent front approaches the edge of the plates. The solvent front was marked and dried at room temperature (Aduku, 2006). At the end, component in a series of spots bands were observed.

The pre-coated TLC plates were manually spotted using capillary tube. The plates were dried and developed in an airtight chromatographic tank at room temperature. Subsequently, spot on the pre-coated TLC plates were visualized under UV light (254-366) $\mathrm{nm}$ after getting sprayed with $10 \%$ sulfuric acid and heated at $110^{\circ} \mathrm{C}$ for $2-5$ minutes.

\subsection{Fourier Transform Infrared Spectrometry (FT-IR)} Analysis of the Isolated Compound from the Methanolic Extract.

Infrared (IR) analysis was used to identify the functional group present in the compound. The functional groups present were determined by their corresponding absorption peaks (band) from the IR analysis spectrum (Figure 1 and 2). Different functional groups are detected using their corresponding absorption peaks (band) by comparing it with their corresponding IR values obtained from literature as shown in (Table 6 and 7). The identification of the functional groups present is one crucial step toward the determination of the isolated compounds which are constituents of the plant extract. These compounds make up the secondary metabolites, and answer the activity of the plant part (leaves) as antimicrobial agents. The information recovered from this spectrometric analysis can allow us to infer and elucidate what our isolated compounds might be.

\section{RESULTS AND DISCUSSION}

\subsection{Phytochemical screening}

The phytochemical Screening of crude methanolic extracts of A. senegalensis revealed the presence of some secondary metabolites such as carbohydrates, steroids, cardiac glycosides, flavonoids, tannins, triterpenes, saponins. Alkaloids and anthraquinone were absent as shown in table 1. The presence of these diversity secondary metabolites in the plant justifies its use as antioxidant due to the presence of flavonoids as well as anti-inflammatory due to the presence of tannins. It is reported to be used to treat many ailments which include the use of leaves decoction as extraordinary remedy for diabetes, yellow fever, small pox and tuberculosis (Ajaiyeoba et al., 2006; Mustapha et al., 2013). Different parts of the tree are used against snake-bite and hernia treatment (Dambatta and Aliyu, 2011).

Table 1: Phytochemical screening of leaves of A. senegalensis

\begin{tabular}{|c|c|}
\hline Test & Interference \\
\hline Glycosides & \\
\hline $\begin{array}{cc}\text { a. } & \text { Anthraquinones } \\
\text { (Bontrager's test) }\end{array}$ & - \\
\hline $\begin{array}{ll}\text { b. } & \text { Cardiac glycosides } \\
\text { (Keller-Killiani test) }\end{array}$ & + \\
\hline
\end{tabular}

\begin{tabular}{|c|c|}
\hline $\begin{array}{c}\text { Steroids/Terpenoids (Lieberman } \\
\text { Burchard test) }\end{array}$ & + \\
\hline Alkaloids (Wagner test) & - \\
\hline Saponins (Frothing test) & + \\
\hline Tannins (Ferric chloride test) & + \\
\hline Flavonoids (Shinoda test) & + \\
\hline Carbohydrates (Molisch's test) & + \\
\hline
\end{tabular}

$+=$ presence,$-=$ absence

\subsection{Antibacterial activity of Annona senegalensis}

The leaves extract of Annona senegalensis showed activity against three of the test organisms Staphylococcus aureus, Escherichia coli and Bacillus subtilis. Determination of inhibitory activity (sensitivity test), that is, diameter of zone of inhibition $(\mathrm{mm})$ at varying concentrations, 100, 50, 25, 12.5 $(\mu \mathrm{g} / \mathrm{ml})$ of the extract, and control of ciprofloxacin $(10 \mu \mathrm{g})$ was shown in table 2. Determination of minimum inhibitory concentration (MIC) and minimum bactericidal concentration (MBC) of the extract against the test organisms was shown in table 3. This indicates that the leaves extract can be used for the treatment of bacterial diseases, since it showed activity against bacteria. These results showed a good correlation with the reported uses of the plant for the treatment of skin diseases as well as skin infection since bacteria is responsible for such illness.

Table 2: Diameter of zone of inhibition $(\mathrm{mm})$ at varying concentration of the extract $(\mu \mathrm{g} / \mathrm{ml})$

\begin{tabular}{|c|c|c|c|c|c|}
\hline \multirow{2}{*}{ Test organism } & \multicolumn{5}{|c|}{ Concentration } \\
\cline { 2 - 6 } & $\begin{array}{c}\mathbf{1 0 0} \\
(\boldsymbol{\mu g} / \mathbf{m l} \\
)\end{array}$ & $\begin{array}{c}\mathbf{5 0} \\
(\boldsymbol{\mu g} / \mathbf{m l} \\
)\end{array}$ & $\begin{array}{c}\mathbf{2 5} \\
(\boldsymbol{\mu g} / \mathbf{m l} \\
)\end{array}$ & $\begin{array}{c}\mathbf{1 2 . 5} \\
(\boldsymbol{\mu g} / \mathbf{m l} \\
)\end{array}$ & $\begin{array}{c}\text { Control } \\
(\mathbf{c i p r o f l o x a c i} \\
\mathbf{n ~ 1 0 \mu g})\end{array}$ \\
\hline $\begin{array}{c}\text { Staphylococcu } \\
\text { S aureus }\end{array}$ & 20 & 18 & 15 & 11 & 39 \\
\hline $\begin{array}{c}\text { Bacillus } \\
\text { subtilis }\end{array}$ & 16 & 13 & 10 & - & 38 \\
\hline $\begin{array}{c}\text { Escherichia } \\
\text { coli }\end{array}$ & 14 & 12 & - & - & 42 \\
\hline $\begin{array}{c}\text { Salmonella } \\
\text { typhi }\end{array}$ & 11 & 16 & - & - & 40 \\
\hline $\begin{array}{c}\text { Klebsiella } \\
\text { pneumonia }\end{array}$ & - & - & - & - & 38 \\
\hline
\end{tabular}

Table 3: Minimum inhibitory concentration (MIC) and minimum bactericidal concentration (MBC) of the extract against the test organism $(\mu \mathrm{g} / \mathrm{ml})$

\begin{tabular}{|c|c|c|}
\hline Test organism & (MIC) & (MBC) \\
\hline $\begin{array}{c}\text { Staphylococcus } \\
\text { aureus }\end{array}$ & 12.5 & 25 \\
\hline Bacillus subtilis & 50 & 100 \\
\hline Escherichia coli & 100 & $*$ \\
\hline Salmonella typhi & $*$ & $*$ \\
\hline Klebsiella pneumonia & $*$ & $*$ \\
\hline
\end{tabular}

\section{KEYS}

$\mathrm{mm}=$ Millimeter, $\mu \mathrm{g} / \mathrm{ml}=$ Microgram per milliliter, $*=$ Not determined and $-=$ No activity 


\subsection{Result of Chromatography}

\subsubsection{Thin Layer Chromatography of the Crude Methanolic Extract}

Thin layer chromatography (TLC) was carried out on the ethyl acetate extract, and the result is shown in table 4. Three prominent spots were observed on (TLC) aluminum sheet after spotting and spraying with $10 \% \mathrm{H}_{2} \mathrm{SO}_{4}$ in methanol. The retention factor $\left(\mathrm{R}_{\mathrm{f}}\right)$ of the three spots are $0.833,0.717,0.813$, and 0.644 respectively.

Table 4: TLC of Methanol extract using n-Hexane: ethyl acetate (7:3)

\begin{tabular}{|c|c|c|}
\hline $\begin{array}{c}\text { Distance moved by } \\
\text { Component }\end{array}$ & Solvent front & $\mathbf{R}_{\mathbf{f}}$ value \\
\hline 3.5 & 4.2 & 0.833 \\
\hline 3.3 & 4.6 & 0.717 \\
\hline 2.6 & 3.2 & 0.813 \\
\hline 2.9 & 4.5 & 0.644 \\
\hline
\end{tabular}

3.3.2. Column Chromatography of n-Hexane: ethyl acetate Fractions

Column chromatography was carried out and the result shown in table 5. The column was eluted continuously using different n- Hexane: ethyl acetate solvent systems.

Table 5: Fraction from Column Chromatography of the Methanolic Extract

\begin{tabular}{|c|c|c|}
\hline Fractions & Eluting Solvent & Number of Spot \\
\hline $1-8$ & $\begin{array}{c}\text { n-Hexane }: \text { ethyl acetate } \\
90: 10\end{array}$ & 4 \\
\hline $8-16$ & $\begin{array}{c}\text { n-Hexane : ethyl acetate } \\
80: 20\end{array}$ & 3 \\
\hline $16-22$ & $\begin{array}{c}\text { n-Hexane }: \text { ethyl acetate } \\
70: 30\end{array}$ & 2 \\
\hline $22-31$ & $\begin{array}{c}\text { n-Hexane }: \text { ethyl acetate } \\
60: 40\end{array}$ & 1 \\
\hline
\end{tabular}

3.4. Fourier Transform Infrared spectroscopy (FT-IR) analysis of A. senegalensis

The first isolated compound of the plant extract revealed the presence of some functional group such as $\mathrm{C}-\mathrm{H}$ (alkane) and $\mathrm{C}=\mathrm{O}$ (ketone) for both stretching vibration of the spectrum. The C-H stretch typical of alkane was observed at peak level of $2918 \mathrm{~cm}^{-1}$ which was within the range of $(3000-2850) \mathrm{cm}^{-1}$, and the $\mathrm{C}=\mathrm{O}$ Stretch typical of ketone functional group was observed at peak level of $1736 \mathrm{~cm}^{-1}$ which was within the range of (1760-1665) $\mathrm{cm}^{-1}$. The second isolated compound revealed the presence of some functional group such as $\mathrm{O}-\mathrm{H}$ (alcohol), $\mathrm{C}-\mathrm{H}$ (alkane) and $\mathrm{C}=\mathrm{C}$ (aromatic ring). The $\mathrm{O}-\mathrm{H}$ stretch typical of alcohol was observed at peak level of 3250 $\mathrm{cm}^{-1}$ which was within the range of $(3500-3200) \mathrm{cm}$, the C-H stretch typical of alkane was observed at peak level of 2926 $\mathrm{cm}^{-1}$ which was within the range of (3000-2850) $\mathrm{cm}$, and $\mathrm{C}=\mathrm{C}$ stretch typical of (aromatic ring) was observed at $1561 \mathrm{~cm}^{-1}$ which was within the range of $(1600-1500) \mathrm{cm}^{-1}$. The existence of these compounds with antimicrobial activity against Staphylococcus aureus, Escherichia coli and Bacillus subtilis justifies the use of the leaves extract for the treatment of bacterial diseases, and it can also be used for the development of novel antibacterial drugs.

Table 6: FT-IR Result of Isolated Compound ID Sample 1

\begin{tabular}{|c|c|c|}
\hline $\begin{array}{c}\text { Assigned Functional } \\
\text { Group }\end{array}$ & $\begin{array}{c}\text { Ranges from } \\
\text { Literature }\left(\mathbf{c m}^{-\mathbf{1}}\right)\end{array}$ & $\begin{array}{c}\text { Observed } \\
\text { Peaks }\left(\mathbf{c m}^{-1}\right)\end{array}$ \\
\hline C-H (alkane stretch) & $3000-2850$ & 2918 \\
\hline C=O (ketone stretch) & $1760-1665$ & 1736 \\
\hline
\end{tabular}

Table 7: FTIR Result of Isolated Compound ID Sample 2

\begin{tabular}{|c|c|c|}
\hline $\begin{array}{c}\text { Assigned Functional } \\
\text { Group }\end{array}$ & $\begin{array}{c}\text { Ranges from } \\
\text { Literature }\left(\mathbf{c m}^{\mathbf{- 1}}\right)\end{array}$ & Observed Peaks $\left(\mathbf{c m}^{\mathbf{- 1}}\right)$ \\
\hline O-H (alcohol stretch) & $3500-3200$ & 3250 \\
\hline C-H (alkane stretch) & $3000-2800$ & 2926 \\
\hline $\begin{array}{c}\text { C=C (aromatic ring } \\
\text { stretch) }\end{array}$ & $1600-1500$ & 1561 \\
\hline
\end{tabular}

\section{Agilent Technologies}

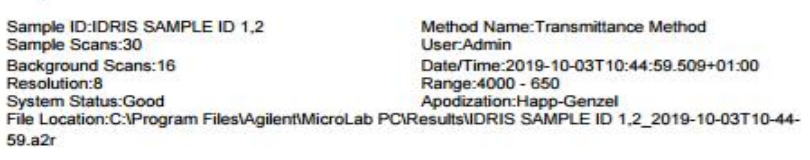
File.a2r

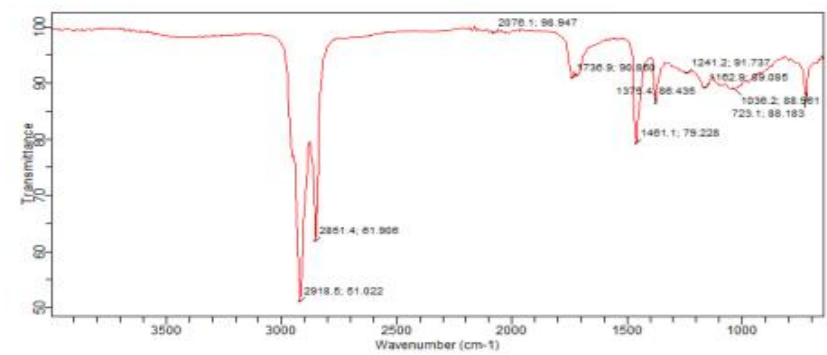

Figure 1. Fourier Transform Infrared spectroscopy (FTIR) analysis of the isolated compound $\mathrm{ID}_{1}$

\section{Agilent Technologies}
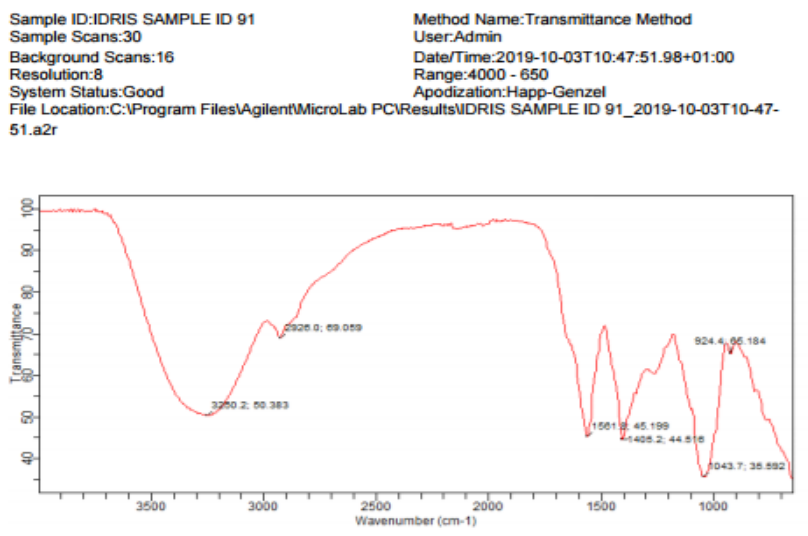

Figure 2. Fourier Transform Infrared spectroscopy (FTIR) analysis of the isolated compound $\mathrm{ID}_{2}$ 


\section{CONCLUSION}

The phytochemical screening showed that the leaves of Annona senegalensis contain Steroids, Cardiac glycosides, Flavonoids, Tannins, Triterpenes, Glycosides and Saponins. The plant extract also showed antimicrobial activity against the test organisms (Bacillus subtilis, Staphylococcus aureus and Escherichia coli). The IR analysis of the test/purified extracts also revealed the presence of carbonyl and alkanol functional groups which are characteristic of the phytochemicals. Thus, it is concluded from the above study that the medicinal properties of Annona senegalensis might be due to the presence of these bioactive compounds and other phytochemicals, and it could therefore be used as a source of antioxidant as well as anti-inflammatory chemicals.

\section{ACKNOWLEDGEMENTS}

The authors would like to thank the entire academic staffs, laboratory technicians and librarian of the department of chemistry, Ahmadu Bello University Zaria for their kind support during the research work.

\section{REFERENCES}

[1] Aduku, O. (2006). Phytochemistry and antimicrobial screening of Gardenia erubescens leaves. Journal of Chemical Society of Nigeria, 10(3): 398-402.

[2] Andrews, J. M. (2001). Determination of a minimum inhibitory concentrations. Journal of Antimicrobial Chemotherapy, 48(1): 516.

[3] Abdullahi, M. N., Ilyas, N., Ibrahim, H. (2013). Evaluation of phytochemical screening and analgesic activity of aqueous extract of the leaves of Microtrichia perotitii dc (Asteraceae) in mice using hotplate method. Medicinal Plant Research, 3(5): 37-43.

[4] Ayoola, G. A., Coker, H. B., Adesegun, S. A., Adepoju-Bello, A. A., Obaweya, K., Ezennia, E. C. and Atangbayila, T. O. (2008). Phytochemical screening and antioxidant activities of some selected medicinal plants used for malaria therapy in southwestern Nigeria. Tropical Journal of Pharmaceutical Research, 7(3): 10191024.

[5] Ajaiyeoba, E., Falade, M., Ogbole, O., Okpako, L. and Akinboye, D. (2006). In vivo antimalarial and cytoxic properties of Annona senegalensis extract. African Journal of Traditional, Complementary and Alternative Medicine, 3(1):137-141.

[6] Banso, A. and Adeyemo, S. (2006). Phytochemical screening and antimicrobial assessment of Abutilon mauritianum, Bacopa monnifera and Datura stramonium. Biokemistri, 18(1): 39-44.

[7] Doughari, J. H. (2012). Phytochemicals: extraction methods, basic structures and mode of action as potential chemotherapeutic agents. InTech, 2012, 9-10.

[8] Dambatta, S. and Aliyu, B. (2011). A survey of major ethnomedicinal plants of Kano North, Nigeria, their knowledge and uses by traditional healers. Bayero Journal of Pure and Applied Sciences 4(2): 28-3.

[9] Genellin, C. R. and Roberts, S. M. (1999). Medicinal chemistry: The role of organic chemistry in drug research (2nd Ed.). Academic Press Limited, pp. 122-123.

[10] Girish, H. V. (2008). Antibacterial activity of some important medicinal plants on human pathogenic bacteria- A comparative analysis. World Applied Science Journal, 5(3): 267-271.

[11] Iqbal, E., Salim, K. A. and Lim, L. B. L. (2015). Phytochemical screening, total phenolics and antioxidant activities of bark and leaf extracts of Goniothalamus velutinus (Airy Shaw) from Brunei Darussalam. Journal of King Saud University - Science, 2015(27): 224-232.

[12] Joshi, A., Bhobe, M., and Saatarkar, A. (2013). Phytochemical investigation of the roots of Grewia microcos Linn. Journal of Chemical and Pharmaceutical Research, 5(7): 80-87.

[13] Kar, A. (2007). Pharmacognosy Pharmacobiotechnology (Revised-Expanded Second Edition). New Age International Limited Publishers, New Delhi, pp 332-600.

[14] Kinston, W. (2008). Irish contribution to the origins of antibiotic. Irish Journal of Medicinal Sciences. 177(2): 82-87.

[15] Miliauskas, G., Venskutonis, P. R., Beek, T. A. (2004). Screening of radical scavenging activity of some medicinal and aromatic plant extracts. Food Chemistry, 85, 231-237.

[16] Mustapha, A., Owuna, G. and Uthman, I. (2013). Plant remedies practical by Keffi people in the management of Dermatosis. Journal of medicinal plants studies, 1(5): 112-118.

[17] Ngbolua, K. N., Moke, E. L., Baya, J. L., Djoza, R., Ashande, C. M. and Mpiana, P. T. (2017). A mini-review on the pharmacognosy and phytochemistry of a tropical medicinal plant: Annona senegalensis Pers. (Annonaceae). Tropical Plant Research 4(1): 168-175.

[18] Nweze, E. L; Okafor, J. L. and Njuku O. (2004). Antimicrobial activities of methanolic extracts of trumeguineesis (Scchumn and Thom) and Morinda Lucinda used in Nigerian herbal medicinal practice. Journal of Biological Research and Biotechnology. 2(1): 34-46. 